\title{
Factors Associated with Fistula Secondary Failure in Patients on Hemodialysis Safwat Farrag ${ }^{1}$, Ahmed El Ashkar ${ }^{1}$, Ahmed Aboul Fotouh ${ }^{2}$, Mohamed El Shorbagy ${ }^{3}$, Ahmed Ibrahim ${ }^{1}$ \\ Internal Medicine \& Nephrology ${ }^{1}$, Radiology ${ }^{2}$ and Clinical Pathology ${ }^{3}$ Departments, Faculty of Medicine Al-Azhar University. \\ Corresponding author: Ahmed Ibrahim, email:drahmedibrahim14@yahoo.com
}

\begin{abstract}
Background: Native arteriovenous (AV) fistulas, which are the most commonly used access line, enable sufficient and repeated hemodialysis (HD) applications and improves the rate of survival and quality of life in patients with end-stage renal disease (ESRD) when performed timely in an appropriate anatomic location using a fine technique. Objectives: We aimed to assess factors responsible for fistula secondary failure in patients on hemodialysis. Patients and Methods: Thirty patients with end stage renal disease (ESRD) on regular HD were included. All patients underwent history taking, clinical examination and ultrasound examination was carried out for all patients to assess AVF and factors associated with its patency and failure. Results: There was no statistically significant differences between group I and group II as regards to age, BMI, HD duration and AVF age ( $\mathrm{p}$-value $>0.05$ ). There was statistically high significant difference between patients with well functioning AVF (group I) and patients with malfunctioning (secondary failed) AVF (group II) as regarding SVP and mean arterial blood pressure (P-value $<0.01)$ and there was statistically significant difference between group I and group II as regarding DVP ( $\mathrm{p}$-value $<0.05)$. There was statistically high significant difference between group I and group II as regarding venous diameter and FV (P-value $<0.01$ ), while there was no statistically significant difference between group I and group II as regarding arterial diameter (P-value > 0.05). There was statistically high significant difference between group I and group II as regarding hemoglobin \& dialysis adequacy (Kt/V) (P-value < 0.01). Conclusion: The native AVF is the vascular access of choice for patients who require hemodialysis: it lasts longer and is associated with fewer complications than other types of vascular access; for hemodialysis patients, these benefits translate into better quality of life and longer survival. The result of this study showed a significant positive correlation between access blood flow (Qa) and Kt/V. This confirm the importance of well-functioning non stenotic AVF in delivering adequate dialysis.
\end{abstract}

Key words: HD: Hemodialysis, AVF: Arteriovenous fistula, ESRD: End stage renal disease, Qa: Access blood flow, Kt/V: Dialysis adequacy.

\section{INTRODUCTION}

End-stage renal disease is a chronic disease requiring treatment with dialysis or renal transplantation. Patients require an adequate vascular access for hemodialysis (HD). Autologous arteriovenous fistula (AVF) is gold standard to maintain vascular access for HD ${ }^{(1)}$. Vascular access-related complications can lead to patient morbidity and reduction of patient quality of life ${ }^{(2)}$. The complication rate related to permanent $\mathrm{HD}$ vascular access remains relatively high and access related problems are responsible for $50 \%$ of the hospitalization of dialysis patients ${ }^{(3)}$. Secondary failures are not rare and in need of adequate attention and care. Once the AVF has been placed. It is recommended that serial monitoring of the AVF should be done for long term effective function. Delays in preventing complications may lead to AVF dysfunction. However, little is known about the factors determining long term prognosis of an $\mathrm{AVF}^{(4)}$. The fistulae were then followed-up by means of non-invasive measurement of diameter and blood flow using an ultrasonic colour flow scanner. The echo color Doppler ultrasound (CDUS) allows a detailed morphological and functional vascular access (VA) assessment; it is a cheap and non-invasive technique, suitable for the study of superficial structures, it does not use contrast agents and it is becoming a tool directly used by nephrologists. In fact Doppler ultrasound is an excellent and sensitive modality for hemodialysis access evaluation and important not only as a preoperative tool, but also in post-operative monitoring of AVF maturation. The current guidelines recommend AVF surveillance by access blood flow measurement and the correction of hemodynamic stenosis if present in order to prolong access survival. In conclusion Doppler ultrasound is readily available, easily used by nephrologists, non-invasive, safe, inexpensive, reproducible, although it requires more clinical skill and time to perform and proper equipment. Furthermore, ultrasonography imaging can substantially reduce the number of subsequent invasive angiographic procedures ${ }^{(5)}$.

\section{PATIENTS AND METHODS}

A thirty patients with end stage renal disease (ESRD), on regular HD in Dialysis Unit, Internal Medicine Department, Al-Hussein Hospital, Faculty of Medicine, Al-Azhar University-Egypt, were recruited to participate in 
our study. Those with dialysis vintage shorter than three months or being dialysed via catheter or graft were excluded from our study. The study was approved by the Ethics Board of Al-Azhar University.

All patients were under regular haemodialysis (HD) four hours thrice weekly through AVF. They were all dialysed through a native AVF by Freseinus 4008S Machine, using bicarbonate dialysis solution.

In this study, Patients were divided in to 2 groups:- Group (I): Included 15 patients on regular hemodialysis with well functioning AVF by physical examination and duplex ultrasound. Group (I I): Included15 patients on regular hemodialysis with malfunctioning (secondary failed) AVF by physical examination and duplex ultrasound.

\section{All subjects in this study were subjected to the following:}

1-History and clinical examination stressing on: Thorough history taking. Duration of dialysis. Detailed physical examination of AVF.

2-Laboratory Investigations to evaluate: $\mathrm{Hb}(\mathrm{g} / \mathrm{dl})$, serum creatinine $(\mathrm{mg} / \mathrm{dl})$, blood urea (mg/dl), fasting blood glucose levels (mg/dl), serum cholesterol $(\mathrm{mg} / \mathrm{dl})$ and serum triglycerides (TG) $(\mathrm{mg} / \mathrm{dl})$, Serum calcium $(\mathrm{Ca})(\mathrm{mg} / \mathrm{dl})$, serum phosphorus (Po4) (mg/dl), Ca x Po4 product and intact parathyroid hormone (iPTH) $(\mathrm{pg} / \mathrm{ml})$.

3- Duplex US examination of AVF: To assess access blood flow (Qa), evidence of stenosis, thrombosis and other abnormalities that could be detected. We used Qa $<500 \mathrm{ml} / \mathrm{min}$ as diagnostic cut off point for fistula dysfunction ${ }^{(6,7)}$.

Access flow was determined by equipment software using the formula below:

Flow volume $(\mathrm{mL} / \mathrm{min})=\operatorname{TAV}(\mathrm{cm} / \mathrm{sec}) \times \pi \mathrm{r}^{2}$

(cross -sectional area in $\left.\mathrm{cm}^{2}\right) \times 60(8)$.

Ultrasound examination was carried out using ultrasound color flow scanner (Toshiba Xario with a $5-12 \mathrm{MHz}$ linear-array transducer). The fistulas were screened from the feeding artery (brachial artery in the mid-arm or radial artery in the forearm) via anastomosis and upward to the upper arm. The flow measurement of the feeding artery (supplier proximal artery to the shunt) was taken two $\mathrm{cm}$ above the fistula. Since precise determination of the maximum velocity and velocity ratio in the anastomotic area was very difficult, due to the limitations of ultrasound examination and the lack of proper angle correction as mentioned by other investigators $(9,10)$. We measured the flow volume in the brachial and feeding artery of the shunt to evaluate the AVFs.

To reduce errors to an acceptable level, we carried out the measurements twice and used the mean results. If the second measurement varied by $>10 \%$, then a third measurement was performed and the mean of the two closest measurements were recorded. DU studies were performed by a radiologist who was not aware of the clinical, laboratory or hemodialysis status when performing the ultrasound examination.

4-Adequacy of dialysis: assessed by the $\mathrm{Kt} / \mathrm{V}$ formula ${ }^{(11)}$.

\section{RESULTS}

As regards demographic data, their mean age was $38.50 \pm 14.21$ years old, 17 were males and 13 were females, their body mass index (BMI) was $26.61 \mathrm{~kg} / \mathrm{m} 2( \pm 5.77)$, the mean hemodialysis duration was 33.73 months $( \pm 24.58)$ and their AVF age was 19.01 months $( \pm 17.14)$. There was no statistically significant differences between group I and group II as regards to age, BMI, HD duration and AVF age (p-value >0.05). There was statistically high significant difference between group I and group II as regards SVP and mean arterial blood pressure (P-value $<0.01)$ and there was statistically significant difference between group I and group II as regards DVP (p-value < 0.05). There was statistically high significant difference between group I and group II in regard to venous diameter and FV (P-value < 0.01 ), while there was no statistically significant difference between group I and group II as regards arterial diameter (P-value > 0.05). There was statistically high significant difference between group I and group II in regard to hemoglobin \& dialysis adequacy $(\mathrm{Kt} / \mathrm{v})(\mathrm{P}$-value $<0.01)$. While, there was no statistically significant difference between group I and group II as regards serum creatinine, blood urea, S. cholesterol, S. TGs, S. Ca, S. PO4, CaxPO4 product and iPTH (P-value > 0.05) as shown in table (1). There was no statistically significant difference between group I and group II as regards sex (P-value > 0.05). There was statistically high significant difference between group I and group II as regards smoking (P-value < 
0.01). There was statistically significant difference between group I and group II concerning past history of AVF thrombosis (P-value < 0.05). There was no statistically significant difference between group I and group II as regards cause of renal failure (HD cause) (P-value > 0.05) as shown in table (2). There was statistically significant difference between group I and group II as regards prolonged bleeding after removal of HD needles (P-value < 0.05). There was statistically high significant difference between group I and group II concerning difficult cannulation (P-value $<0.01$ ).

Table (1): shows comparison between the two groups as regard laboratory parameters (using Mann-Whitney test).

\begin{tabular}{|c|c|c|c|c|c|}
\hline & Group & Mean & $\begin{array}{c}\text { Std. } \\
\text { Deviation }\end{array}$ & p-value & Significance \\
\hline \multirow{2}{*}{$\mathrm{Hb} \%(>12 \mathrm{~g} / \mathrm{dl})$} & Group 1 & 8.98 & 0.47 & \multirow{2}{*}{$<0.01$} & \multirow{2}{*}{ HS } \\
\hline & Group 2 & 10.57 & 0.95 & & \\
\hline \multirow{2}{*}{$\begin{array}{l}\text { Serum creatinine } \\
(0.5-1.4 \mathrm{mg} / \mathrm{dl})\end{array}$} & Group 1 & 7.98 & 2.35 & \multirow{2}{*}{0.36} & \multirow{2}{*}{ NS } \\
\hline & Group 2 & 8.50 & 1.96 & & \\
\hline \multirow{2}{*}{$\begin{array}{l}\text { Blood urea }(20-40 \\
\mathrm{mg} / \mathrm{dl})\end{array}$} & Group 1 & 113.33 & 28.68 & \multirow{2}{*}{0.49} & \multirow{2}{*}{ NS } \\
\hline & Group 2 & 123.13 & 33.45 & & \\
\hline \multirow{2}{*}{ FBS $(60-110 \mathrm{mg} / \mathrm{dl})$} & Group 1 & 98.87 & 37.89 & \multirow{2}{*}{0.63} & \multirow{2}{*}{ NS } \\
\hline & Group 2 & 117.20 & 34.25 & & \\
\hline \multirow{2}{*}{$\begin{array}{l}\text { Serum cholesterol } \\
(<200 \mathrm{mg} / \mathrm{dl})\end{array}$} & Group 1 & 158.73 & 56.92 & \multirow{2}{*}{0.98} & \multirow{2}{*}{ NS } \\
\hline & Group 2 & 153.13 & 56.13 & & \\
\hline \multirow{2}{*}{$\mathrm{TG}(<150 \mathrm{mg} / \mathrm{dl})$} & Group 1 & 177.47 & 35.48 & \multirow{2}{*}{0.62} & \multirow{2}{*}{ NS } \\
\hline & Group 2 & 168.47 & 27.32 & & \\
\hline \multirow{2}{*}{$\begin{array}{l}\text { Serum calcium }(\mathrm{Ca}) \\
(8.4-9.5 \mathrm{mg} / \mathrm{dl})\end{array}$} & Group 1 & 8.97 & 1.18 & \multirow{2}{*}{0.79} & \multirow{2}{*}{ NS } \\
\hline & Group 2 & 8.74 & .92 & & \\
\hline \multirow{2}{*}{$\begin{array}{l}\text { Serum PO4 (3.5-5.5 } \\
\mathrm{mg} / \mathrm{dl})\end{array}$} & Group 1 & 5.71 & 1.65 & \multirow{2}{*}{0.49} & \multirow{2}{*}{ NS } \\
\hline & Group 2 & 5.39 & 1.76 & & \\
\hline \multirow{2}{*}{ CAXPO4 $(<55)$} & Group 1 & 51.40 & 17.58 & \multirow{2}{*}{0.38} & \multirow{2}{*}{ NS } \\
\hline & Group 2 & 47.54 & 17.80 & & \\
\hline \multirow{2}{*}{$\begin{array}{l}\text { iPTH (150-300 } \\
\mathrm{pg} / \mathrm{ml})\end{array}$} & Group 1 & 300.47 & 20.97 & \multirow{2}{*}{0.17} & \multirow{2}{*}{ NS } \\
\hline & Group 2 & 378.76 & 58.53 & & \\
\hline \multirow[b]{2}{*}{$\mathrm{Ktlv}(>1.2)$} & Group 1 & 1.20 & .10 & \multirow{2}{*}{$<0.01$} & \multirow{2}{*}{ HS } \\
\hline & Group 2 & .95 & .12 & & \\
\hline
\end{tabular}

According to K/DOQI guidelines.

There was statistically high significant difference between group I and group II as regards hemoglobin \& dialysis adequacy (Kt/v) (P-value < 0.01 ), while there was no statistically significant difference between group I and group II in regard to serum creatinine, blood urea, S. cholesterol, S. TGs, S. Ca, S. PO4, CaxPO4 product and iPTH (Pvalue $>0.05$ ).
Table (2): shows comparison between the two groups as regard clinical parameters (HD cause) (by Chi-Square test).

\begin{tabular}{|c|c|c|c|c|c|c|}
\hline & \multicolumn{2}{|c|}{ Group } & \multirow[b]{2}{*}{$\begin{array}{c}\text { p- } \\
\text { value }\end{array}$} & \multirow[b]{2}{*}{ Significance } \\
\hline & & & \begin{tabular}{|c|} 
Group \\
1
\end{tabular} & $\begin{array}{c}\text { Group } \\
\mathbf{2}\end{array}$ & & \\
\hline & HTN & $\begin{array}{l}\text { Number } \\
\text { o within }\end{array}$ & 6 & $\begin{array}{c}4 \\
267 \%\end{array}$ & & \\
\hline & DM & Number & 2 & 2 & & \\
\hline & & $\%$ within group & $13.3 \%$ & $13.3 \%$ & & \\
\hline & $\begin{array}{l}\text { veflux } \\
\text { refleterie }\end{array}$ & $\begin{array}{l}\text { Number } \\
\% \text { within group }\end{array}$ & $\begin{array}{c}1 \\
67 \%\end{array}$ & $\begin{array}{c}2 \\
13.3 \%\end{array}$ & & \\
\hline & \begin{tabular}{|l|} 
Obstructive \\
\end{tabular} & Number & 1 & 2 & & \\
\hline & uropathy & $\%$ within group & $6.7 \%$ & $13.3 \%$ & & \\
\hline $\begin{array}{l}\mathrm{HD} \\
\text { cause }\end{array}$ & Lupus nephriti & Number & 1 & 1 & & \\
\hline & & $\%$ within group & $6.7 \%$ & $6.7 \%$ & & \\
\hline & Chronic GN & $\begin{array}{l}\text { Number } \\
\% \text { within groun }\end{array}$ & $\begin{array}{c}2 \\
133 \%\end{array}$ & $\begin{array}{c}0 \\
0 \%\end{array}$ & & NS \\
\hline & \begin{tabular}{|l|} 
Analgesic \\
\end{tabular} & Number & 1 & 0 & 0.33 & \\
\hline failure) & nephropathy & $\%$ within group & $6.7 \%$ & $0 \%$ & & \\
\hline & Bilateral PKD & Number & 1 & $\begin{array}{c}1 \\
670\end{array}$ & & \\
\hline & & Number & 0 & 1 & & \\
\hline & nephropathy & $\%$ within group & $0 \%$ & $6.7 \%$ & & \\
\hline & Pre-_clamnsi & Number & 0 & 1 & & \\
\hline & Pre- eclampsia & $\%$ within group & $0 \%$ & $6.7 \%$ & & \\
\hline & unknown & Number & 0 & 1 & & \\
\hline & & $\%$ within group & $0 \%$ & $6.7 \%$ & & \\
\hline
\end{tabular}

There was no statistically significant difference between group I and group II as regards cause of renal failure (HD cause) (P-value > 0.05).

\section{DISCUSSION}

The prevalence of end stage kidney disease has been increasing during the last three decades in Egypt.

Most of these patients were receiving their haemodialysis treatment session via arteriovenous fistula (AVF). Actually, creating this type of access is considered very vital for haemodialysis patients. It enables them to avoid serious complication of long use of haemodialysis catheters e.g. local and systemic infections as well as unachieved required dialysis adequacy.

Approximately a quarter to one third of created fistulas failed to ever be used with an even higher risk in the elderly (>65 years); and by one year, over half of all fistulas failed or required at least one intervention (radiological or surgical). Furthermore, failure of AVF is well known to be associated with significant morbidity and mortality.

For this reasons, we investigated factors associated with late fistula failure i.e. failure after three months of usage.

This study analysed patients with functional AVFs, which had successfully matured and were used for dialysis, to determine risk factors 
for subsequent loss of primary functional patency after use.

In this study, all patients in group 2 were recruited after failure to insert haemodialysis needles due to impalpable fistula; a through history taken, examination and fistula assessment were done as well as data were collected from patients haemodialysis files regarding the previous haemodialysis sessions.

In the current study, age, sex, body mass index, haemodialysis duration and fistula age were not significantly different between both groups. In contrary to primary fistula failure, in which all these factors are important determinant of primary success of the AVF as previously reported by Lok et al. and Stoumpos et al. ${ }^{(12,13)}$.

These results gave us the impression that these factors lose its significance as pivotal players in maintaining fistula function as long as the fistula passes the first three months.

In addition, our results went in partial disagreement with previous studies carried out by Monroy-Cuadros et al. identified age and history of diabetes and smoking as independent risk factors for fistula failure after 6 months of first usage ${ }^{(14)}$.

In this study, on examination of the failed fistulae, we found that the mean flow was around 100 $\mathrm{ml} / \mathrm{min}$ which gave us the impression that despite the fistula was dead clinically, a flow is still can be detected which gave chance for fistula salvage.

Going back to look for risk factors that should have drawn our attention towards fistula malfunction, we found that markers of elevated venous pressure i.e. history of difficult needles cannulation or prolonged bleeding after needles removal, positive arm elevation test and elevated static and dynamic venous pressure measurements were significantly different between both groups which gave us the impression that these patients suffered from venous stenosis which may be either juxta -anastomotic or central one.

The risk of thrombosis increases with the degree of stenosis. KDOQI guidelines define significant stenosis of the vessel lumen as a reduction by more than $50 \%$. Clinical suspicion of stenosis is confirmed by the presence of several factors: reduced quality of dialysis, problems with puncture, such as prolonged bleeding after AVF puncture, pain in the area of the fistula or increased venous pressure. It usually occurs near a stenosis in the area of anastomosis or fistula vein ${ }^{(15)}$.

Besides, we noticed a highly significant difference between both groups as regards marker of efficient dialysis i.e. $\mathrm{Kt} / \mathrm{V}$ in preceding three months before fistula failure.

This finding highlighted the importance of investigating the integrity of AVF in every patient presented with low $\mathrm{Kt} / \mathrm{V}$.

In this study, the findings went in agreement with Campos et al. and Bashar et al. who found that $\mathrm{Kt} / \mathrm{V}$ decreased significantly in patients with stenosis of the vascular access ${ }^{(16,17)}$.

$\mathrm{Kt} / \mathrm{V}$ decreased significantly in patients with stenosis of the vascular access which may be due to the decrease in the blood flow rate in AVF and recirculation of blood. Recirculation occurs when dialyzed blood returning through the venous needle re-enters the extracorporeal circuit through the arterial needle, rather than returning to the systemic circulation that leads to decrease in urea removal and decrease $\mathrm{Kt} / \mathrm{V}^{(18)}$.

Recirculation is an important issue since it appears to be a significant cause of inadequate HD. The most common cause is the presence of high-grade venous stenosis, which obstruct venous outflow, leading to backflow into the arterial needle ${ }^{(19)}$.

In our study we found that pre-dialysis blood pressure was significantly lower in failed fistula group. Our results went in agreement with Culp et al. who specifically described predialysis diastolic pressure as a predictor of risk of thrombosis in AVFs and grafts in the first year after creation ${ }^{(20)}$. A subsequent prospective series of 463 patients also reported that a low mean diastolic pressure correlated with poorer AVF survival after exclusion of patients with early fistula failure from the study ${ }^{(21)}$.

On the other hand, no any significant difference was found between both groups regarding abnormality in the arterial loop of the fistula i.e. arterial diameter.

The possible explanation is that we did not find significant difference between both groups as regards risk factors for atherosclerosis i.e. history of HTN and DM, high levels of triglycerides and cholesterol as well as risk factors for arterial wall calcification as calcium, phosphorus, calcium phosphorus product and intact parathyroid hormone levels. 


\section{CONCLUSION}

The native AVF is the vascular access of choice for patients who required hemodialysis. It lasts longer and is associated with fewer complications than other types of vascular access; for hemodialysis patients. These benefits translate into better quality of life and longer survival.

The results of this study showed a significant positive correlation between access blood flow (Qa) and $\mathrm{Kt} / \mathrm{v}$. This confirmed the importance of well-functioning non stenotic AVF in delivering adequate dialysis.

Finally, a multidisciplinary approach (nephrologists, surgeons, radiologists and nurses) should improve the HD outcome by promoting the use of AVF.

\section{REFERENCES}

1. Manne V, Vaddi SP, Reddy VB et al. (2017): Factors Influencing Patency of Brescia-Cimino Arteriovenous Fistulas in Hemodialysis Patients. Saudi J Kidney Dis Transpl., 28 (2):313-317.

2. MacRae J, Dipchand $\mathrm{C}$, Oliver $\mathrm{M}$ et al. (2016): Arteriovenous Access Failure, Stenosis, and Thrombosis. Canadian Journal of Kidney Health and Disease, 3: 1- 11.

3. Moghazy Kh (2009): Value of Color Doppler Sonography in the Assessment of Hemodialysis Access Dysfunction. Saudi J Kidney Disease Transplant, 20(1):35-43.

4. Kahraman S, Özden E, Başeskioğlu B et al. (2003): Native Arteriovenous Fistula in Hemodialysis Patients: The Impact of Clinical, Nutritional, Inflammatory, Atherosclerotic and Genetic Factors on Prognosis. BANTAO Journal, 1 (2): 154-156.

5. Mudoni A, Caccetta F, Caroppo $M$ et al. (2016): Echo color Doppler ultrasound: a valuable diagnostic tool in the assessment of arteriovenous fistula in hemodialysis patients. $\mathbf{J}$ Vasc Access., (1): 1-7.

6. Tonelli M, Jhangri GS, Hirsch DJ et al. (2003): Best Threshold for Diagnosis of Stenosis or Thrombosis within Six Months of Access Flow Measurement in Arteriovenous Fistulae. J Am Soc Nephrol., 14: 3264-3269.
7. Rajabi-Jaghargh E, Banerjee RK (2015): Combined functional and anatomical diagnostic endpoints for assessing arteriovenous fistula dysfunction. World $\mathrm{J}$ Nephrol., 4(1): 6-18.

8. Zamboli P, Fiorini F, Amelio A et al. (2014): Color Doppler ultrasound and arteriovenous fistulas for hemodialysis. J Ultrasound, 17:253-263.

9. Alamdaran A, Nazemian F, Taheri $\mathbf{H}$ (2008): Doppler Ultrasound Assessment of Well-Functioning Native Hemodialysis Access: Comparison with Sufficient Dialysis. Iran J Radiol., 5(1):101-105.

10. Van Hooland S, Donck J, Ameye F et al. (2010): Duplex Ultrasonography and Haemodialysis Vascular Access: A Practical Review. Int J Nephrol Urol., 2(2): 283 - 293.

11. Daugirdas JT, Leypoldt JK, Akonur A et al. (2013): Improved equation for estimating single-pool Kt/V at higher dialysis frequencies. Nephrol Dial Transplant., 28: 2156-2160.

12. Lok CE, Allon M, Moist L et al. (2006): Risk equation determining unsuccessful cannulation events and failure to maturation in arteriovenous fistulas (REDUCE FTM I). Am J Soc Nephrol., 17: 3204-12.

13. Stoumpos S, Stevens KK, Aitken $\mathbf{E}$ et al. (2014): Predictors of sustained arteriovenous access use for haemodialysis. Am J Nephrol., 39:491-498.

14. Monroy-Cuadros M, Yilmaz S, SalazarBañuelos A et al. (2010): Risk Factors Associated with Patency Loss of Hemodialysis Vascular Access within 6 Months. Clin. J. Am. Soc. Nephrol., 5: 1787-1792.

15. KDOQI (2006): Clinical Practice guidelines for vascular access.Am J Kidney Dis., 48:176322.

16. Campos RP, Do Nascimento M, Chula DC et al. (2006): Stenosis in hemodialysis arteriovenous fistula: Evaluation and treatment. Hemodialysis International, 10:152-161.

17. Bashar K, Conlon PJ, Kheirelseid EA et al. (2016): Arteriovenous fistula in dialysis patients: factors implicated in early and late AVF maturation failure. Surgeon, 14:294-300. 
18. Ghonemy A, Farag S, Soliman S et al. (2016): Vascular access complications and risk factors in hemodialysis patients: A single center study. Alexandria Journal of Medicine, 52(1):67-71.

19. Almasri J, Alsawas M, Mainou $M$ et al. (2016): Outcomes of vascular access for hemodialysis: a systematic review and metaanalysis. J Vasc Surg., 64:236-243.
20. Culp K, Flanigan M, Taylor L et al. (1995): Vascular access thrombosis in new hemodialysis patients. Am J Kidney Dis., 26:341-6.

21. Puskar D, Pasini J, Savic' I et al. (2002): Survival of primary arteriovenous fistula in 463 patients on chronic hemodialysis. Croat Med J., 43:306-11. 